\title{
Superantigenic exotoxin production by isolates of Staphylococcus aureus from the Kawasaki syndrome patients and age-matched control children
}

\author{
Y. TODOME, H. OHKUNI, M. MIZUSE, F. OKIBAYASHI, N. OHTANI, H. SUZUKI, C. SONG, \\ H. IGARASHI*, K. HARADA†, S. SAKURAI $\$$ and S. KOTANI§
}

\begin{abstract}
Division of Immunology, Institute of Gerontology, Nippon Medical School, 1-396 Kosugi-cho, Nakahara-ku, Kawasaki 211, * Department of Microbiology, Tokyo Metropolitan Research Laboratory of Public Health, Sinjyuku-ku, Tokyo 160, † Department of Microbiology, Osaka Prefectural Institute for Public Health, Higashi-ku, Osaka 537, $\ddagger$ Division of Molecular Genetics, Jikei University School of Medicine, Minato-ku, Tokyo 105 and $\S$ Osaka College of Medical Technology, Kita-ku, Osaka 530, Japan
\end{abstract}

\begin{abstract}
Summary. Nineteen strains of Staphylococcus aureus were isolated from the throat or the tooth surfaces of 19 cases amongst 127 patients with Kawasaki syndrome (KS) during the acute phases and $11 \mathrm{~S}$. aureus isolates were obtained from five of 17 diseased controls and six healthy controls. The production of exotoxins, particularly superantigenic toxic shock syndrome toxin-1 (TSST-1), coagulase serotype, pigment production, haemolytic activity and tryptophan auxotrophy of these isolates were compared. Among $10 \mathrm{KS} S$. aureus strains isolated in 1990-1991, five (50\%) secreted TSST-1, a higher frequency than two (18\%) of 11 control isolates. In contrast, none of the nine KS strains collected in 1984 produced TSST-1. Four of five TSST-1-secreting KS strains produced white or white to golden pigmentation, whereas the two control strains capable of TSST-1 production formed golden colonies. There were no noticeable differences between $S$. aureus strains from KS patients and control children in the production of staphylococcal exotoxins A-E, coagulase serotype, haemolysis of sheep erythrocytes and tryptophan auxotrophy. The pathological or aetiological role of a new TSST-1-secreting $S$. aureus clone in patients with KS was not confirmed.
\end{abstract}

\section{Introduction}

A bacteriological study of 256 clinical isolates from the throat and tooth surfaces of 89 patients with Kawasaki syndrome (KS), and 85 isolates from 17 agematched patients with infections other than KS and six healthy children revealed that over half of both KS and control isolates were gram-positive and catalasenegative cocci, and about $50 \%$ of these were classified as viridans group streptococci. Concentrated culture supernates of these viridans streptococci were examined for dermatotoxicity in rabbit skin, aggregation of human blood platelets, ${ }^{1,2}$ cytokine induction in human and murine macrophages ${ }^{3}$ and superantigenicity for human $T$ cells (unpublished data).

The second major bacterial group isolated from the KS patients and control children comprised grampositive, and catalase-positive cocci (broadly grouped as Staphylococcus spp. and Micrococcus spp.) which accounted for 17 and $20 \%$ of the KS and control isolates, respectively. ${ }^{1,2}$
Recently, Leung et al. ${ }^{4}$ identified a novel clone of $S$. aureus which was isolated at a high rate from patients with KS. This novel $S$. aureus clone was characterised by the production of high levels of TSST-1, white pigmented colonies, tryptophan auxotrophy, and diminished production of lipase, haemolysin and protease. None of these characteristics were found in the $S$. aureus isolates from the disease control children with fever or rash, or both, who did not fulfil the diagnostic criteria of KS.

Therefore, we closely examined our stock strains of $S$. aureus isolated from KS patients and control (diseased and healthy) children, paying special attention to the production of superantigenic exotoxins.

\section{Materials and methods}

\section{Test bacteria}

$S$. aureus strains from three sources were studied. (1) Swabs taken from the throat and tooth surfaces of $89 \mathrm{KS}$ patients, 17 not KS but diseased, and six healthy control children at the Japan Red Cross Medical 
Centre (Tokyo, Japan) and Nippon Medical School (Kawasaki, Kanagawa, Japan) in 1990 and 1991. As described previously, ${ }^{1,2}$ swab specimens were transported from the clinic to the laboratory in $\mathrm{CO}_{2}$ enriched anaerobic transport medium (Kenki Porter, Clinical Supply, Gifu, Japan) transferred to GAM semi-solid medium (Gifu Anaerobic Medium; Nissui Corp., Tokyo, Japan) and cultured at $37^{\circ} \mathrm{C}$ for 24-48 h. Bacterial isolates were streaked on pairs of Columbia sheep blood agar plates (bioMérieux, Marie l'Etoile, France). One plate of each pair was cultured aerobically and the other incubated anaerobically in Gas Pak holding jars (Becton Dickinson Microbiology System, Cockeysville, MD, USA) at $37^{\circ} \mathrm{C}$ for $24 \mathrm{~h}$. Single colonies were isolated, and maintained in GDO medium (Nissui Corp.) at $-20^{\circ} \mathrm{C}$ until use. Test bacteria were streaked again on Columbia agar plates and cultured aerobically at $37^{\circ} \mathrm{C}$ overnight. Catalase production was measured with a single colony. ${ }^{5} \mathrm{Gram}$ positive and catalase-positive coccal strains isolated from the KS and control children were then identified according to their biochemical activities with an API Staph kit (bioMérieux, LaBalme les Grottes, France) as $S$. aureus, $S$. epidermidis, $S$. auricularis, $S$. cohnii, Micrococcus spp. and others.

(2) S. aureus strains isolated in 1984 from $38 \mathrm{KS}$ inpatients, 33 diseased children and one healthy control child at the Japan Red Cross Medical Centre served as additional test bacteria. Throat swabs in Transwab (Medical Wire and Equipment Ltd) were transported from the clinic to the laboratory, and cultured anaerobically (Gas Pak; Becton Dickinson Microbiology System) on sheep blood 5\% Trypticase Soy Agar (Becton Dickinson Microbiology System) at $37^{\circ} \mathrm{C}$ for $48 \mathrm{~h}$ as described previously. ${ }^{6}$ Colonies showing macroscopic characteristics of staphylococci were streaked on Mannitol-Salt-Egg Yolk Agar (Nissui Corp.) to select mannitol-fermenting and egg yolk reaction-positive colonies. Nine KS and one healthy control isolates of $S$. aureus thus obtained were suspended in a medium consisting of skim milk (Difco) $10 \mathrm{~g}$, glucose $3 \mathrm{~g}$ and cystine $0.1 \mathrm{~g}$ in $100 \mathrm{ml}$ and stored at $-20^{\circ} \mathrm{C}$ without subculture for nearly 10 years.

(3) Three $S$. aureus strains found in specimens collected in 1993 from healthy children $<6$ years old also served as test bacteria.

\section{Coagulase typing}

S. aureus strains were typed by neutralisation in vitro with rabbit anti-coagulase sera according to the method of Ushioda et al. ${ }^{7}$ Briefly, the test staphylococci were inoculated into Brain Heart Infusion Broth (Difco) containing citrated rabbit blood plasma $5 \%$, and grown at $37^{\circ} \mathrm{C}$ for $18 \mathrm{~h}$, and $0.1-\mathrm{ml}$ volumes were distributed amongst nine tubes; $100 \mu$ l of rabbit anticoagulase type I-VIII sera were placed in the first eight tubes. The ninth tube containing $0.1 \mathrm{ml}$ of normal rabbit serum $5 \%$ served as a control. After incubation at $37^{\circ} \mathrm{C}$ for $1 \mathrm{~h}, 0.2 \mathrm{ml}$ of citrated normal rabbit plasma $10 \%$ was added to all the tubes, which were incubated again at $37^{\circ} \mathrm{C}$. Plasma coagulation was checked repeatedly after $1,2,4$ and 6 and $14 \mathrm{~h}$ to detect inhibition of coagulation.

\section{Pigment production}

Each strain was cultured on Staphylococcus Medium 110 (Eiken Chemical Co. Ltd, Tokyo, Japan) at $37^{\circ} \mathrm{C}$. The colour of the developing bacterial lawn was determined after incubation for 24 and $42 \mathrm{~h}$, and classified as gold (G), white (W) and white to gold $(\mathrm{W} / \mathrm{G})$ pigmentation. $\mathrm{W} / \mathrm{G}$ indicates that the test strain gave white colonies after cultivation for $24 \mathrm{~h}$ and changed to gold during cultivation for a further $18 \mathrm{~h}$.

\section{Haemolysis}

Each strain was cultured on Columbia sheep blood agar and the extent of haemolysis around the colonies was arbitrarily graded: - , no haemolysis; + , partial haemolysis; and ++ , clear haemolysis.

\section{Tryptophan auxotrophy}

Each strain of $S$. aureus was cultured in $3 \mathrm{ml}$ of brain heart infusion broth at $37^{\circ} \mathrm{C}$ for $18 \mathrm{~h}$, and divided into two equal portions. One portion was washed twice by centrifugation with a chemically-defined medium $(\mathrm{CDM}){ }^{8}$ The cells suspended in CDM $(0.5 \mathrm{ml})$ were inoculated into $10 \mathrm{ml}$ of CDM. The other half was similarly washed in CDM without tryptophan $[\mathrm{CDM}(-)]$, and inoculated into $\operatorname{CDM}(-)$. After incubation at $37^{\circ} \mathrm{C}$ for 24 or $48 \mathrm{~h}$, the growth of test strains in $\mathrm{CDM}$ and $\mathrm{CDM}(-)$ was compared. $S$. aureus strains with good growth in CDM but no or poor growth in $\mathrm{CDM}(-)$ were judged to be tryptophan auxotrophs.

\section{Detection of TSST-1 and SEA-SEE}

Exotoxin production was examined by means of the reversed latex agglutination test as described previously. ${ }^{9,10}$ Briefly, a $5 \%$ suspension of latex particles (SLD-59, 0.9 $\mu$ m diameter; Takeda Chemical Industries Ltd, Osaka, Japan) was diluted 1 in 10 with $67 \mathrm{~mm}$ phosphate-buffered saline (PBS, pH 7.2), containing $\mathrm{NaN}_{3} 0.05 \%$, then mixed with an equal volume of affinity-purified rabbit anti-TSST-1 and antistaphylococcal exotoxin (SEA-SEE) antibody solution containing protein $60 \mu \mathrm{g} / \mathrm{ml}$ in PBS, and the mixture was incubated at $37^{\circ} \mathrm{C}$ for $30 \mathrm{~min}$. The latex particles sensitised with each antibody were washed thoroughly with PBS, and suspended at a final concentration of $0.025 \%$ in PBS supplemented with bovine serum albumin (Fraction V) (Seikagaku Kogyo Co., Ltd, Tokyo, Japan) $0.83 \%$ and polyvinylpyrrolidine (Wako Pure Chemical Industries, Ltd, Osaka) $0.004 \%$.

Each $S$. aureus strain was grown in brain heart 
Table 1. Characterisation of $S$. aureus isolates from throat and tooth swabs of KS patients

\begin{tabular}{|c|c|c|c|c|c|c|c|c|c|c|c|}
\hline \multirow{2}{*}{$\begin{array}{c}\text { Strain } \\
\text { no. (site) }\end{array}$} & \multicolumn{2}{|c|}{ Source } & \multirow[b]{2}{*}{ Pigment* } & \multirow[b]{2}{*}{ Haemolysis $\dagger$} & \multirow{2}{*}{$\begin{array}{l}\text { Coagulase } \\
\text { serotype }\end{array}$} & \multirow{2}{*}{$\begin{array}{l}\text { Tryptophan } \\
\text { auxotrophy }\end{array}$} & \multicolumn{4}{|c|}{ Staphylococcal exotoxin $(\mathrm{ng} / \mathrm{ml})$} & \multirow{2}{*}{$\begin{array}{l}\text { Exfoliatin } \\
\text { (A/B) }\end{array}$} \\
\hline & $\begin{array}{r}\text { Sex/Age } \\
(\mathrm{Y} / \mathrm{M})\end{array}$ & $\begin{array}{l}\text { Date of } \\
\text { collection }\end{array}$ & & & & & SEB & SEC & $\mathrm{SEA} / \mathrm{D} / \mathrm{E}$ & TSST-1 & \\
\hline $13(\mathrm{~T})$ & M 0/08 & 1990 & $\mathrm{~W} / \mathrm{G}$ & ++ & II & - & $<2 \cdot 5$ & 313 & $<2.5$ & 3125 & - \\
\hline $14(\mathrm{P})$ & F $1 / 00$ & 1990 & $\mathrm{G}$ & ++ & III & - & $<2.5$ & $<2.5$ & $<2.5$ & $<5$ & - \\
\hline $21(\mathrm{~T})$ & M 0/03 & 1990 & W & $+t$ & VII & - & $<2.5$ & 313 & $<2.5$ & 625 & - \\
\hline $26(\mathrm{P})$ & F $2 / 10$ & 1990 & G & ++ & II & $+(+)$ & 313 & 63 & $<2.5$ & $<5$ & - \\
\hline $29(\mathrm{P})$ & M $0 / 03$ & 1990 & W & - & VII & - & $<2 \cdot 5$ & 313 & $<2.5$ & 3125 & - \\
\hline $32(\mathrm{P})$ & M $2 / 09$ & 1990 & W & ++ & II & $+(-)$ & 7813 & 313 & $<2 \cdot 5$ & $<5$ & - \\
\hline $35(\mathrm{P})$ & F $1 / 02$ & 1990 & $\mathrm{G}$ & - & VII & $+(-)$ & $<2.5$ & $<2.5$ & $<2 \cdot 5$ & $<5$ & - \\
\hline $39(\mathrm{P})$ & F $0 / 03$ & 1990 & $\mathrm{G}$ & ++ & VII & - & $<2.5$ & $<2.5$ & $<2.5$ & $<5$ & - \\
\hline $42(\mathrm{P})$ & M 4/10 & 1991 & G & ++ & III & - & $<2.5$ & 1563 & $<2.5$ & 625 & - \\
\hline $49(\mathrm{P})$ & F $1 / 10$ & 1991 & $\mathrm{~W} / \mathrm{G}$ & - & VII & - & $<2.5$ & 1563 & $<2.5$ & 625 & - \\
\hline $53(\mathrm{P})$ & M 1/07 & 1984 & G & ++ & VII & - & $<2.5$ & $<2.5$ & $<2.5$ & $<5$ & $\mathrm{nt}$ \\
\hline $54(\mathrm{P})$ & F $0 / 10$ & 1984 & $\mathrm{~W} / \mathrm{G}$ & ++ & VII & - & $<2.5$ & $<2.5$ & $<2.5$ & $<5$ & $\mathrm{nt}$ \\
\hline $56(\mathrm{P})$ & M $1 / 10$ & 1984 & $\mathrm{G}$ & ++ & VII & - & $<2.5$ & $<2.5$ & 313 (SED) & $<5$ & $\mathrm{nt}$ \\
\hline $58(\mathrm{P})$ & M 0/05 & 1984 & $\mathrm{G}$ & ++ & III & - & $<2.5$ & $<2.5$ & $<2 \cdot 5$ & $<5$ & nt \\
\hline $60(\mathrm{P})$ & F $0 / 06$ & 1984 & $\mathrm{G}$ & ++ & VII & - & $<2.5$ & $<2.5$ & $<2.5$ & $<5$ & nt \\
\hline $61(\mathrm{P})$ & M $2 / 05$ & 1984 & $\mathrm{G}$ & ++ & III & - & $<2.5$ & $<2.5$ & $<2 \cdot 5$ & $<5$ & $\mathrm{nt}$ \\
\hline $63(\mathrm{P})$ & F $1 / 11$ & 1984 & $\mathrm{G}$ & ++ & VII & - & $<2.5$ & $<2.5$ & 1563 (SED) & $<5$ & nt \\
\hline $65(\mathrm{P})$ & M 0/03 & 1984 & G & ++ & III & $+(-)$ & $<2.5$ & $<2.5$ & $<2.5$ & $<5$ & nt \\
\hline $67(\mathrm{P})$ & M $0 / 02$ & 1984 & G & ++ & II & - & $<2.5$ & $<2.5$ & 313 (SED) & $<5$ & $\mathrm{nt}$ \\
\hline
\end{tabular}

$\mathrm{T}$, isolated from tooth surface; $\mathrm{P}$, isolated from pharynx; $\mathrm{M}$, male; $\mathrm{F}$, female; nt, not tested.

* Colour of colonies after growth for $24 \mathrm{~h}$ and $42 \mathrm{~h}$ on Staphylococcus Medium 110 at $37^{\circ} \mathrm{C}$; G, gold; W, white; W/G, white after cultivation for $24 \mathrm{~h}$ and gold after $42 \mathrm{~h}$.

$\dagger++$, formation of a clear haemolytic zone around the colony grown on sheep blood $5 \%$ agar; + , a turbid haemolytic zone; - , no haemolysis.

$\ddagger+$, no growth in a tryptophan deleted, chemically defined medium, CDM $(-)$ after incubation for $24 \mathrm{~h}$; - , no difference between the growth in CDM and CDM (-); ( ), judged after incubation for $48 \mathrm{~h}$.

infusion broth in test tubes at $37^{\circ} \mathrm{C}$ for $16-18 \mathrm{~h}$ with shaking at $100 \mathrm{rpm}$. and $25-\mu 1$ portions of serial fivefold dilutions of each culture supernate were dispensed in the wells of a U-bottom, 96-well microtitration plate (Nunc, Roskild, Denmark). To each well was added $25 \mu \mathrm{l}$ of latex particles sensitised with anti-TSST-1 or anti-SEA-SEE antibody. The wells were mixed thoroughly and incubated for $16 \mathrm{~h}$ at room temperature. Agglutination of the sensitised latex particles was examined macroscopically by means of light transmitted through the bottom of the plates. The level of TSST-1 and SEA-SEE production was semiquantified by determining the highest dilution of test culture supernate giving a positive reaction when the sensitivity of the assay in terms of minimum detection concentration was $1 \mathrm{ng} / \mathrm{ml}$ for TSST- 1 and $0.5 \mathrm{ng} / \mathrm{ml}$ for SEA-SEE.

\section{Detection of exfoliatin $A$ and $B$}

Exfoliatin A and B levels were determined as described previously. ${ }^{11}$ Briefly, each strain was grown in trypticase-yeast medium (TY medium) ${ }^{11}$ at $37^{\circ} \mathrm{C}$ overnight in air $+\mathrm{CO}_{2} 5 \%$. Culture supernate $(0 \cdot 1 \mathrm{ml}$; heated or not at $60^{\circ} \mathrm{C}$ for $30 \mathrm{~min}$ ) was injected subcutaneously into the backs of neonatal $\mathrm{C} 3 \mathrm{H} / \mathrm{He}$ mice (Nippon Biosupply Centre, Tokyo, Japan) within 2-3 days of birth; $16 \mathrm{~h}$ later, they were examined for general exfoliation and a positive Nikolsky sign. The heat-stable and heat-labile exfoliatins were designated exfoliatin A and B, respectively.

\section{Results}

Tables I and II show the origin, coagulase serotype, pigment production, haemolytic activity and tryptophan auxotrophy of $19 \mathrm{~S}$. aureus isolates from 19 patients with KS, and those of 11 control strains isolated from five diseased and six healthy control children. There were no significant differences in coagulase serotypes between the KS and control isolates except that the incidence of serotype VII was higher in KS strains than in control isolates. The proportion of serotype II, III and VII strains were four ( $21 \%$ ), five (26\%) and $10(53 \%)$ among $19 \mathrm{KS}$ strains. The corresponding values were three $(27 \%)$, three $(27 \%)$ and three $(27 \%)$ among 11 control strains (one each of serotype $\mathrm{V}$ and unknown serotype were found among the controls). Six (32\%) of 19 KS strains formed white or white/gold colonies on Staphylococcus Medium 110 whereas only two (18\%) of 11 control isolates did so. No difference was noted in tryptophan auxotrophy between the KS and control strains; four $(21 \%)$ of 19 versus two (18\%) of 11.This was true for a comparison of haemolytic activity on sheep blood; $16(84 \%)$ of 19 of the KS strains were haemolytic and all of the control isolates were haemolytic.

A distinct, though not statistically significant, difference was noted in TSST-1 production between 10 KS strains collected during 1990-1991 and 11 strains from the diseased and healthy controls. The isolation rates of TSST-1 secreting strains were five ( $50 \%)$ of 10 
Table II. Characterisation of S. aureus isolates from throat and tooth swabs of non-KS patients and healthy children

\begin{tabular}{|c|c|c|c|c|c|c|c|c|c|c|c|}
\hline \multirow{2}{*}{$\begin{array}{l}\text { Strain } \\
\text { no. (site) }\end{array}$} & \multicolumn{2}{|l|}{ Source } & \multirow[b]{2}{*}{ Pigment } & \multirow[b]{2}{*}{ Haemolysis } & \multirow{2}{*}{$\begin{array}{l}\text { Coagulase } \\
\text { serotype }\end{array}$} & \multirow{2}{*}{$\begin{array}{l}\text { Tryptophan } \\
\text { auxotrophy }\end{array}$} & \multicolumn{4}{|c|}{ Staphylococcal exotoxin (ng/ml) } & \multirow{2}{*}{$\begin{array}{l}\text { Exfoliatin } \\
\text { (A/B) }\end{array}$} \\
\hline & $\begin{array}{r}\text { Sex/Age } \\
(\mathrm{Y} / \mathrm{M})\end{array}$ & $\begin{array}{l}\text { Date of } \\
\text { collection }\end{array}$ & & & & & SEB & SEC & $\mathrm{SEA} / \mathrm{D} / \mathrm{E}$ & TSST-1 & \\
\hline $8(\mathbf{P})$ & $\begin{array}{l}\text { M } 2 / 07 \\
\text { (Viral pneumonia) }\end{array}$ & 1990 & G & + & III & $+(-)$ & $<2 \cdot 5$ & 313 & $<2.5$ & 125 & A \\
\hline $16(P)$ & $\begin{array}{l}\text { M } 1 / 04 \\
\text { (Acute bronchitis) }\end{array}$ & 1990 & G & ++ & VII & - & $<2 \cdot 5$ & $<2 \cdot 5$ & 13 (SEA) & $<5$ & $\mathrm{nt} \rrbracket$ \\
\hline $22(\mathrm{P})$ & $\begin{array}{l}\text { F } 0 / 03 \\
\text { (Acute bronchitis) }\end{array}$ & 1990 & G & + & II & - & $<2 \cdot 5$ & 313 & $<2 \cdot 5$ & 625 & - \\
\hline $36(P)$ & $\begin{array}{l}\text { M 1/01 } \\
\text { (Viral meningitis) }\end{array}$ & 1990 & G & ++ & VII & - & $<2 \cdot 5$ & $<2.5$ & $<2 \cdot 5$ & $<5$ & nt \\
\hline $71(\mathrm{P})$ & $\begin{array}{l}\text { M 2/01 } \\
\text { (Acute respiratory } \\
\text { infection) }\end{array}$ & 1984 & G & ++ & Unknown & $+(-)$ & $<2 \cdot 5$ & $<2 \cdot 5$ & $<2 \cdot 5$ & $<5$ & nt \\
\hline $41(\mathrm{P})$ & $\begin{array}{l}\text { M 4/11 } \\
\text { (Healthy) }\end{array}$ & 1991 & G & ++ & III & - & $<2 \cdot 5$ & 1563 & $<2 \cdot 5$ & $<5$ & - \\
\hline $52(\mathrm{P})$ & $\begin{array}{l}\text { F } 1 / 01 \\
\text { (Healthy) }\end{array}$ & 1991 & W & ++ & II & - & 7813 & 7813 & $<2.5$ & $<5$ & - \\
\hline $70(\mathrm{P})$ & $\begin{array}{l}\text { F } 1 / 03 \\
\text { (Healthy) }\end{array}$ & 1984 & G & ++ & III & - & $<2 \cdot 5$ & $<2.5$ & $<2 \cdot 5$ & $<5$ & $\mathrm{nt}$ \\
\hline $76(\mathrm{P})$ & $\begin{array}{l}\text { F } 5 \\
\text { (Healthy) }\end{array}$ & 1993 & G & ++ & V & - & $<2.5$ & $<2 \cdot 5$ & $<2 \cdot 5$ & $<5$ & nt \\
\hline $77(\mathrm{P})$ & $\begin{array}{l}\text { M } 3 \\
\text { (Healthy) }\end{array}$ & 1993 & $\mathrm{G}$ & ++ & VII & - & $<2 \cdot 5$ & $<2 \cdot 5$ & $<2 \cdot 5$ & $<5$ & nt \\
\hline $83(\mathrm{P})$ & $\begin{array}{l}\text { F } 5 \\
\text { (Healthy) }\end{array}$ & 1993 & W & ++ & II & - & 3906 & $<2 \cdot 5$ & $<2.5$ & $<5$ & nt \\
\hline
\end{tabular}

Other gram-positive and catalase-positive coccal strains not included in the above list: $S$. epidermidis (three strains), and Micrococcus spp. (two). Strain nos. 8, 16, 22, 36 and 71 were from non-KS patients with various infections as indicated in parentheses (diseased controls), and other strains came from healthy children (healthy controls). Abbreviations as in table I.

Table III. Comparison of exotoxin production by $S$. aureus isolates from KS patients and controls

\begin{tabular}{|c|c|c|c|c|c|}
\hline \multirow{2}{*}{$\begin{array}{l}\text { S. aureus strain } \\
\text { from (number) }\end{array}$} & & \multicolumn{4}{|c|}{ Number $(\%)$ of positive strains } \\
\hline & & SEB & SEC & $\mathrm{SEA} / \mathrm{D} / \mathrm{E}$ & TSST-1 \\
\hline \multicolumn{6}{|l|}{ KS patients } \\
\hline 1990-1991 & (10) & $2(20)$ & $7(70)$ & $0(0)$ & $5(50) \ddagger$ \\
\hline 1984 & (9) & $0(0)$ & $0(0)$ & $3(33)^{*}$ & $0(0)$ \\
\hline Total & (19) & $2(11)$ & $7(37)$ & $3(16)^{*}$ & $5(26)$ \\
\hline \multicolumn{6}{|c|}{ Control children } \\
\hline diseased & (5) & $0(0)$ & $2(40)$ & $1(20) \dagger$ & $2(40)$ \\
\hline healthy & (6) & $2(33)$ & $2(33)$ & $0(0)$ & $0(0)$ \\
\hline Total & (11) & $2(18)$ & $4(46)$ & $1(9) \dagger$ & $2(18)$ \\
\hline
\end{tabular}

* All three were SED.

+ SEA.

$\ddagger$ Significantly different by Student's $t$ test $(\mathrm{p}<0.05)$.

and two $(18 \%)$ of 11 , respectively. Incidentally, the rate (positive/total strains) of TSST-1 production by the 1990-1991 KS strains was significantly different ( $\mathrm{p}<0.05$ by Student's $t$ test) from that by the healthy control strains; five $(50 \%)$ of 10 versus none $(0 \%)$ of six. Among five TSST-1-producing KS isolates, four (nos. 13, 21, 29 and 49) formed white or white to gold pigment, but one (strain no. 42) gave gold colonies. The two control TSST-1-secreting strains (nos. 8 and 22) produced golden pigmentation. No correlation was found between TSST-1 production, tryptophan auxotrophy and haemolytic activity amongst the KS and control isolates; in contrast to the data presented by
Leung et al. ${ }^{4}$ However, the assay procedures for tryptophan auxotrophy and haemolytic activity differed in the two studies. ${ }^{4}$

The noteworthy finding revealed by the present study is that none of the nine KS $S$. aureus strains isolated in 1984 produced TSST-1 toxin in contrast to KS isolates, in 1990-1991 and only one of them (strain no. 54) gave white to gold colonies (table I).

Of the other staphylococcal exotoxins, higher levels of SEC were produced by the group of KS strains isolated in 1990-1991 (seven of 10,70\%) as compared with $S$. aureus isolates from the diseased and healthy control group (four of $11,46 \%$ ). However, this was not so in KS strains isolated in 1984 (none of nine) (table III). All three SED-producing strains were found amongst the $1984 \mathrm{KS}$ isolates. No exfoliatin was produced by the $10 \mathrm{KS}$ strains isolated in 1990-1991, whereas one (strain no. 8) of the four diseased control isolates secreted exfoliatin A, although the scope of the assay was limited (tables I and II).

\section{Discussion}

Leung et al. ${ }^{4}$ reported that six (55\%) of $11 \mathrm{~S}$. aureus strains isolated from the throat swabs of $16 \dot{\mathrm{KS}}$ patients produced TSST-1 that may stimulate $\mathrm{V} \beta 2+\mathrm{T}$ cells which are selectively expanded in the blood of $\mathrm{KS}$ patients during the acute phase of the illness, ${ }^{12}$ whereas only one TSST-1-producing $S$. aureus strain was isolated from 15 diseased controls. Furthermore, they found that if all the $S$. aureus isolates from the throat, 
rectum, axilla and groin of the $\mathrm{KS}$ patients were combined, the isolation rate of TSST-1-secreting $S$. aureus strains reached $81 \%$ (13 positive among 16 cases). They also reported that isolates from $\mathrm{KS}$ patients were white in contrast to the typical gold colonies of coagulase-positive $S$. aureus strains.

The present study revealed that five $(50 \%)$ of $10 \mathrm{~S}$. aureus isolates from the throat and tooth swabs of KS patients collected in 1990-1991 produced TSST-1, whereas the isolation rate of TSST-1-secreting $S$. aureus strains in the diseased and healthy control group was $18 \%$ (two positive among a total of 11 strains) (table III). Four of the five TSST-1-secreting KS strains produced white or white to gold pigment. Thus, since TSST-1 production by 1990-1991 KS strains correlated with pigmentation, these results are in some agreement with those of Leung et al. ${ }^{4}$. It may be noted that the isolation rate of $S$. aureus from KS patients in the present study was significantly lower than that of Leung et al. ${ }^{4}-10$ strains $(11 \%)$ from 89 cases in 1990-1991 isolates ${ }^{2}$ and nine strains (24\%) from 38 cases in 1984 isolates. $^{6}$

We cannot explain the discrepancy in TSST-1 production between 1990-1991 KS and 1984 KS strains. It may reflect a recent shift in $S$. aureus populations as regards TSST-1 production. Another possibility may be that the new clone of TSST-1producing $S$. aureus, such as that proposed by Leung et $a l^{4}$, may have been lost selectively during the maintenance of the 1984 strains in our laboratory for nearly 10 years. This is improbable considering that

\section{References}

1. Ohkuni $\mathrm{H}$, Todome $\mathrm{Y}$, Igarashi $\mathrm{H}$ et al. Possible etiological role in Kawasaki disease of viridans group streptococci producing erythrogenic toxin: report on the project study of the Research Committee on Kawasaki Disease, Japan Heart Foundation. In: Takahashi M, Taubert K (eds) Proceedings of the Fourth International Symposium on Kawasaki Disease. Dallas, American Heart Association, 1993: 60-76.

2. Ohkuni H, Todome $\mathrm{Y}$, Mizuse $\mathbf{M}$ et al. Biologically active extracellular products of oral viridans streptococci and the aetiology of Kawasaki disease. J Med Microbiol 1993; 39: 352-362.

3. Takada $\mathrm{H}$, Kawabata $\mathrm{Y}$, Tamura $\mathrm{M}$ et al. Cytokine induction by extracellular products of oral viridans group streptococci. Infect Immun 1993; 61 : 5252-5260.

4. Leung YM, Meissner HC, Fulton DR, Murray DL, Kotzin BL, Schlievert PM. Toxic shock syndrome toxin-secreting Staphylococcus aureus in Kawasaki syndrome. Lancet 1993; 342: 1385-1388.

5. Muller HE. ABTS peroxidase medium as a highly sensitive plate assay for detection of hydrogen peroxidase production in bacteria. J Microbiol Methods 1984; 2: 101-102.

6. Harada K, Katsukawa R, Kotani S et al. Bacteriological study on the etiology of Kawasaki disease (MCLS)-search for non- $\beta$ haemolytic bacteria capable of producing exotoxins similar to streptococcal pyrogenic exotoxin. Pediatr Jpn 1986; 27: 921-928 (in Japanese).

7. Ushioda H, Terayama T, Sakai S, Zen-Yoji H, Nishiwaki M, Hidano A. Coagulase typing of Staphylococcus aureus and its application in routine work. In: Jeljaszewicz $\mathbf{J}$ (ed) Staphylococci and staphylococcal infection. Stuttgart, Gustav Fischer. 1981: 77-83. these strains were kept suspended in skim milk at $-20^{\circ} \mathrm{C}$ without subculturing to minimise possible mutation and selection until their recent recovery.

Curtis et al ${ }^{13}$ have examined TSST production by $S$. aureus isolates from the throat and nose of KS patients and their relatives (20 each), and found that both groups harboured two TSST-secreting strains. Nishiyori et al. ${ }^{14}$ have also reported that in 17 of $18 \mathrm{KS}$ patients during the acute phase, serum TSST-1 levels were below the sensitivity level of the method, and anti-TSST antibody did not rise during either acute or convalescent phases in $\mathrm{KS}$ patients who did not receive intravenous $\gamma$ globulin. Furthermore, Abe et al. ${ }^{15}$ and Takeda et al. ${ }^{16}$ have presented experimental results which do not support the claim of Leung et al. ${ }^{4}$

The present studies showed that group A streptococci could not be isolated from either KS patients or control children in clinical specimens collected in $1984^{6}$ and 1990-1991, ${ }^{1,2}$ although Leung et al. ${ }^{4}$ reported that two of $16 \mathrm{KS}$ patients carried Streptococcus pyogenes. The discrepancy may be at least partly explained by the significantly higher age group of $\mathrm{KS}$ children tested in Leung's study than in ours.

In conclusion, further study is needed to evaluate the pathological or aetiological role of a new toxic shock syndrome toxin-secreting $S$. aureus clone in patients with Kawasaki syndrome.

This study was supported in part by a grant from the Japan Heart Foundation.

8. van de Rijn I, Kessler RE. Growth characteristics of group A streptococci in a new chemically defined medium. Infect Immun 1980; 27: 444448.

9. Igarashi H, Fujikawa H, Shingaki M, Bergdoll MS. Latex agglutination test for staphylococcal toxic shock syndrome toxin 1. J Clin Microbiol 1986; 23 : 509-512.

10. Fujikawa $H$, Igarashi $H$. Rapid latex agglutination test for detection of staphylococcal exotoxins $\mathrm{A}$ to $\mathrm{E}$ that uses high-density latex particles. Appl Environ Microbiol 1988; 54: 2345-2348.

11. Kondo I, Sakurai S, Sarai Y. Purification of exfoliatin produced by Staphylococcus aureus of bacteriophage group 2 and its physicochemical properties. Infect Immun 1973; 8: 156-164.

12. Abe J, Kotzin BL, Meissner C et al. Characterization of $\mathrm{T}$ cell repertoire changes in acute Kawasaki disease. J Exp Med $1993 ; 177$ : 791-796.

13. Curtis N, Chan B, Levin M. Toxic shock syndrome toxinsecreting Staphylococcus aureus in Kawasaki syndrome. Lancet 1994; 343: 299.

14. Nishiyori A, Sakaguchi M, Kato H, Igarashi H, Miwa K. Toxic shock syndrome toxin-secreting Staphylococcus aureus in Kawasaki syndrome. Lancet 1994; 343: 299-300.

15. Abe J, Takeda T, Kosaka T, Kobayashi N. Specificity of T cell $\mathrm{V} \beta$ stimulated by superantigen producing bacteria isolated from patients with Kawasaki disease. Abstract of the 13th National Conference of Kawasaki Disease, 1993: 43 (in Japanese).

16. Takeda T, Abe J, Kosaka T, Kobayashi N. Characterization of $S$. aureus strains isolated from the throat of patients with Kawasaki disease. Abstract of the 13th National Conference of Kawasaki Disease, 1993: 45 (in Japanese). 